\title{
North Atlantic Interdecadal Variability: Oceanic Response to the North Atlantic Oscillation (1865-1997)
}

\author{
Carsten Eden and Thomas Jung \\ Institut für Meereskunde, Kiel, Germany
}

(Manuscript received 8 November 1999, in final form 17 April 2000)

\begin{abstract}
In contrast to the atmosphere, knowledge about interdecadal variability of the North Atlantic circulation is relatively restricted. It is the objective of this study to contribute to understanding how the North Atlantic circulation responds to a forcing by the North Atlantic oscillation (NAO) on interdecadal timescales. For this purpose, the authors analyze observed atmospheric and sea surface temperature (SST) data along with the response of an ocean general circulation model to a realistic monthly surface flux forcing that is solely associated with the NAO for the period $1865-1997$.

In agreement with previous studies, it is shown that the relationship between the local forcing by the NAO and observed SST anomalies on interdecadal timescales points toward the importance of oceanic dynamics in generating SST anomalies. A comparison between observed and modeled SST anomalies reveals that the model results can be used to assess interdecadal variability of the North Atlantic circulation.

The observed/modeled developments of interdecadal SST anomalies during the periods 1915-39 and 196084 against the local damping influence from the NAO can be traced back to the lagged response (10-20 yr) of the North Atlantic thermohaline circulation and the subpolar gyre strength to interdecadal variability of the NAO. Additional sensitivity experiments suggest that primarily interdecadal variability in the surface net heat flux forcing associated with the NAO governs interdecadal changes of the North Atlantic circulation.
\end{abstract}

\section{Introduction}

In his pioneering article, Bjerknes (1964) introduced the concept of the timescale dependent nature of North Atlantic air-sea interaction. He suggested that sea surface temperature (SST) anomalies on interannual timescales may solely be explained by a local forcing from the atmosphere. On the other hand, the explanation of interdecadal SST anomalies along the Gulf StreamNorth Atlantic current extension requires additional contributions from oceanic dynamics (altered currents). This conclusion was supported by the observed development/persistence of interdecadal SST anomalies against the local damping influence from the atmosphere. According to Bjerknes, therefore, on interannual timescales, the ocean reacts merely passively to changes of the overlying atmosphere whereas on interdecadal timescales, the ocean circulation plays a role in generating SST anomalies. Bjerknes' hypothesis has been essentially supported by recent observational (Deser and Blackmon 1993; Kushnir 1994) and modeling studies (Delworth et al. 1993; Delworth 1996). From the ob-

Corresponding author address: Dr. Thomas Jung, Institut für Meereskunde, Universität Kiel, Düsternbrooker Weg 20, D-24105 Kiel, Germany.

E-mail: tjung@ifm.uni-kiel.de servations, however, it is still unclear whether interdecadal changes of the subtropical gyre strength (Bjerknes 1964) or the Atlantic thermohaline circulation (THC) (Kushnir 1994) contributed to the development of interdecadal SST anomalies. On the other hand, there is a consensus that interdecadal changes of the North Atlantic oscillation (NAO) were involved (Bjerknes 1964; Deser and Blackmon 1993; Kushnir 1994). The NAO is the dominant mode of atmospheric variability in the North Atlantic region (Cayan 1992a) and describes the simultaneous strengthening and weakening of the Iceland low and Azores high (Walker 1924; Hurrell 1995).

In recent years, coupled general circulation models (CGCMs) of different complexity became valuable tools in climate research. Among others, they were used to investigate the physics of extratropical air-sea interaction. Latif and Barnett (1994) found evidence for the presence of a two-way interaction between the Aleutian low and North Pacific subtropical gyre in the coupled ECHO model. By analyzing the same integration (ECHO model), Grötzner et al. (1998) suggest the existence of a very similar mode in the North Atlantic basin. The dominant timescale of the coupled North Atlantic air-sea mode as simulated by the ECHO model is about $17 \mathrm{yr}$ whereas the realization of interdecadal variability, as described by Bjerknes, points toward timescales of about $40 \mathrm{yr}$ or longer. 
Kushnir's suggestion that interdecadal variability of the THC was of importance during the twentieth century is supported by the spatial pattern of interdecadal SST variability, which shows a striking similarity to those obtained from the coupled GFDL for an anomalously strong THC (Delworth et al. 1993). In this model, however, the relationship between the SST pattern and the NAO seems to be reversed compared to the observations (Delworth et al. 1993). Further evidence for the importance of interdecadal THC variability is put forward by Timmermann et al. (1998), who describe an integration of the coupled ECHAM3/LSG model. Although the mechanisms for the generation of THC variability seem to be somewhat different compared to the GFDL model, Timmermann et al. (1998) find a relationship between the interdecadal SST pattern and the NAO that closely resembles those in the GFDL model. The results by Timmermann et al. (1998) suggest that the warming trend along the Gulf Stream extension from 1894 to 1924, as described by Bjerknes (1964), can be explained by an enhancement of the THC.

Although the results from different CGCMs share some common features with respect to interdecadal THC variability, the physical mechanisms seem to differ among the CGCMs. In a very recent study, Delworth and Greatbatch (2000) show that in contrast to previous studies (Delworth et al. 1993, 1997), interdecadal variability of THC in the GFDL model may be explained by the response of the ocean to internally generated (by the atmosphere) interdecadal variability of the NAO. Moreover, the NAO-related surface net heat flux forcing appears to dominate over the freshwater and momentum flux components. This is in contrast to the ECHAM3/ LSG model, where (i) interdecadal SST anomalies feed back onto the NAO and (ii) interdecadal freshwater flux (primarily evaporation) and wind stress (Ekman transport) variability dominates over the net heat flux component in forcing the ocean (Timmermann et al. 1998).

The advantage of using CGCMs to investigate airsea interaction comes from the fact that the atmosphere and the ocean can freely interact. Moreover, long-term statistics about interdecadal oceanic variability can be obtained from CGCM integrations. A direct comparison with observational results, however, is difficult to carry out. This is because modeled climate trajectories can hardly be merged with the observed realization of interdecadal variability during the twentieth century.

Such a comparison is possible for integrations of ocean general circulation models (OGCMs) that are forced with observed fields of net heat, freshwater, and momentum fluxes (or near-surface atmospheric parameters). These atmospheric forced OGCM experiments are not suited, however, to investigate possible oceanic feedbacks onto the atmosphere. An increasing body of literature deals with this kind of experiments in the North Atlantic (e.g., Halliwell 1998; Häkkinen 1999; Eden and Willebrand 2001, hereafter EW; Kushnir et al. 1999). To our knowledge, all of the studies are re- stricted to the post-World War II period, where the relatively good sampling in the North Atlantic region allows the construction of realiable atmospheric forcing fields. Thus, all these experiments were primarily conducted to investigate variability from interannual to quasidecadal timescales.

The objective of this study is to contribute to our understanding about interdecadal variability of the North Atlantic Ocean. For this purpose, we make use of the following items. First, numerous observational studies (e.g., Bjerknes 1964; Deser and Blackmon 1993; Kushnir 1994; Dickson et al. 1996; Curry et al. 1998) and modeling studies (e.g., Timmermann et al. 1998; Delworth and Greatbatch 2000; Häkkinen 1999; EW) point toward the importance of the NAO in forcing the oceanic circulation. This may be explained by the outstanding role of the NAO in modulating North Atlantic surface fluxes (e.g., Cayan 1992b; Grötzner et al. 1998). Second, sea level pressure (SLP) measurements from the Azores and Iceland, and therefore the NAO index, are available back to the mid-nineteenth century (Hurrell 1995; Jones et al. 1997). Third, after World War II, the sampling in the North Atlantic region became relatively good, and National Centers for Environmental Prediction-National Center for Atmospheric Research (NCEP-NCAR) reanalysis data (Kalnay et al. 1996) provide a full coverage of the surface flux fields for the period 1958-97. Finally, since (i) interdecadal changes of the oceanic circulation seem to leave their imprint on SST anomalies (see above) and (ii) the SST is a relatively well-sampled parameter during the twentieth century in the North Atlantic region, the model results can be assessed.

In this study, the following strategy is used. For each month, spatial patterns of anomalous surface flux fields associated with the NAO are estimated from reanalyzed data for the period 1958-97. Then, the Atlantic OGCM is forced by combining the monthly temporal behavior of the NAO from 1865 to 1997 with the associated monthly surface flux patterns (estimated using data from 1958 to 1997). Thus, during the course of the integration, the OGCM is only driven by the surface flux patterns of net heat, freshwater, and momentum that are linearly associated with the NAO. Then, modeled and observed interdecadal SST anomalies are compared. Finally, interdecadal variability of the oceanic circulation that is solely forced by the NAO is investigated from the OGCM.

The paper is organized as follows. In section 2, a short decription of the model and its forcing is given. A validation of the modeled SST is presented in section 3. The results are given in section 4 . It starts with a description of the observed and modeled interdecadal variability of the NAO and North Atlantic SST anomalies, followed by an analysis of the modeled THC and horizontal gyre variability. Section 4 ends with the description of several sensitivity experiments. The con- 
clusions are briefly summarized in section 5. Finally, the results are discussed in section 6 .

\section{Model and forcing}

The Atlantic OGCM is based on a enhanced version of the GFDL MOM2.1 code (Pacanowski 1995), developed as part of FLAME, a hierachy of models of the Atlantic Ocean (Dengg et al. 1999) (see, e.g., http:// www.ifm.uni-kiel.de/to/flame/). The resolution of the present model is $43^{\circ}$ in longitude and $4 / 3^{\circ} \cos \phi$ in latitude with 45 levels in the vertical. The model domain spans the entire Atlantic from $100^{\circ} \mathrm{W}$ to $30^{\circ} \mathrm{E}$ and $70^{\circ} \mathrm{S}$ to $70^{\circ} \mathrm{N}$. Northern and southern boundaries as well as the Gulf of Cadiz are closed, with zones of climatological forcing for the tracers. The Drake passage and the eastern boundary at $30^{\circ} \mathrm{E}$ are represented as open boundaries after Stevens (1990) with a prescribed inflow and outflow of the Antarctic Circumpolar current. Unresolved subgrid-scale processes are parameterized by harmonic diffusion terms. Temperature and salinity are mixed along neutral surfaces after Cox (1987) and by the eddyinduced tracer advection parameterization of Gent and McWilliams (1990). Horizontal viscosity is chosen as $10^{4} \cos \phi \mathrm{m}^{2} \mathrm{~s}^{-1}$. Vertical diffusivity is set inversely proportional to the static stability of the water column, as proposed by Gargett (1984), and vertical viscosity is set to a constant value of $10^{-3} \mathrm{~m}^{2} \mathrm{~s}^{-1}$. These coefficients are all well-established values for North Atlantic models with $1^{\circ} \times 1^{\circ}$ horizontal resolution. Isopycnal diffusivity and thickness diffusivity is chosen vertically dependent, both with a maximum of $2000 \mathrm{~m}^{2} \mathrm{~s}^{-1}$ in the thermocline decaying with depth to $500 \mathrm{~m}^{2} \mathrm{~s}^{-1}$ (below $4000 \mathrm{~m}$ ). A simple mixed-layer parameterization after Kraus and Turner (1967) is also included in the OGCM.

To obtain a quasidynamical equilibirium of the OGCM, the model was forced with monthly climatological windstress and net heat flux fields taken from Barnier et al. (1995) during 50 yr of a spinup phase, starting from a state of rest and climatological temperatures and salinities. Sea surface salinity was restored toward a monthly climatology during the first $40 \mathrm{yr}$ of the spinup. Thereafter, the model was driven with the diagnosed freshwater flux fields from yr 40. Diagnosed freshwater fluxes were used to reduce the model drift, which may be considerable if observed freshwater fluxes are prescribed (so the drift is small here). For the heat flux forcing, a Haney-type (Haney 1971) boundary condition is used. A restoring term is added to the heat flux forcing in this formulation; the spatially and monthly varying restoring coefficient was determined from a linearization of the net heat flux bulk formulas (Barnier et al. 1995).

Once the spinup was finished, surface flux anomalies were added to the climatologies during the course of the integrations. For the heat flux forcing, however, the anomalies were added to the heat flux term only; the climatological SSTs and the restoring coefficient were not changed (climatological annual cycles as for the spinup). Note that a Haney-type boundary condition for the heat fluxes implies an atmosphere, which is not affected by any SST anomaly generated by the ocean model. For studies of longer-term variability in ocean models, it is common practice to use simplified but reacting models of the atmosphere (e.g., Rahmstorf and Willebrand 1995; Seager et al. 1995). Since the purpose of the present study is to investigate the oceanic reaction to prescribed (NAO related) interdecadal surface flux variability, we cannot use a reacting atmosphere. Therefore, we decided to use a Haney-type condition for heat fluxes. Note that the net, or diagnosed, heat flux forcing of the model differs from the prescribed heat fluxes by a damping term proportional to the restoring coefficient and the SST anomaly produced by the model. The damping term is discussed in more detail in EW; here, it is worth mentioning that the term remains small (compared to the others) throughout the northern North Atlantic. It becomes important in the equatorial region, which is not a focal area of this study.

Monthly forcing fields for the period 1865-1997 that are solely governed by the NAO were constructed as follows. First, monthly NAO-related spatial forcing patterns were obtained by regressing anomalous fields of monthly surface net heat fluxes, wind stress, and freshwater fluxes, taken from the NCEP-NCAR reanalysis (Kalnay et al. 1996), onto the normalized monthly NAO index for the relatively well-sampled period 1958-97. Then, the NAO-related forcing for each month from 1865 to 1997 was reconstructed by multiplying the normalized monthly NAO index (1865-1997) with the associated regressions patterns of surface net heat flux, wind stress, and freshwater flux (estimated from the period 1958-97). Here, the NAO index, defined as the difference between normalized SLP from the Azores and Iceland (Rogers 1984), is used. By using the SLP time series from the Azores instead of Gibraltar or Lisboa as a proxy for the southern center of NAO variability, it is ensured that the out-of-phase variability between the Azores high and Icelandic low is captured even during the summer months (Hurrell and van Loon 1997).

The model shows the typical mean state for mediumresolution GFDL-type Atlantic OGCMs: the maximum annual mean strength of the $\mathrm{THC}$ at $45^{\circ} \mathrm{N}$ and a depth of $1000 \mathrm{~m}$ amounts to $18 \mathrm{~Sv}\left(1 \mathrm{~Sv}=10^{6} \mathrm{~m}^{3} \mathrm{~s}^{-1}\right)$; the maximum annual mean northward meridional heat transport (MHT) amounts to approximately 0.9 PW (PW $\left.=10^{15} \mathrm{~W}\right)$ at $25^{\circ} \mathrm{N}$ and decreases toward $0.6 \mathrm{PW}$ at $48^{\circ} \mathrm{N}$.

The variability of these integral oceanic parameters from the OGCM's long-term integration with the reconstructed NAO forcing is in good agreement with estimates from an integration of the same OGCM with the full forcing fields from the NCEP-NCAR reanalysis during the overlapping period 1958-97 [for details on the latter integration, see EW]. Cross correlations be- 

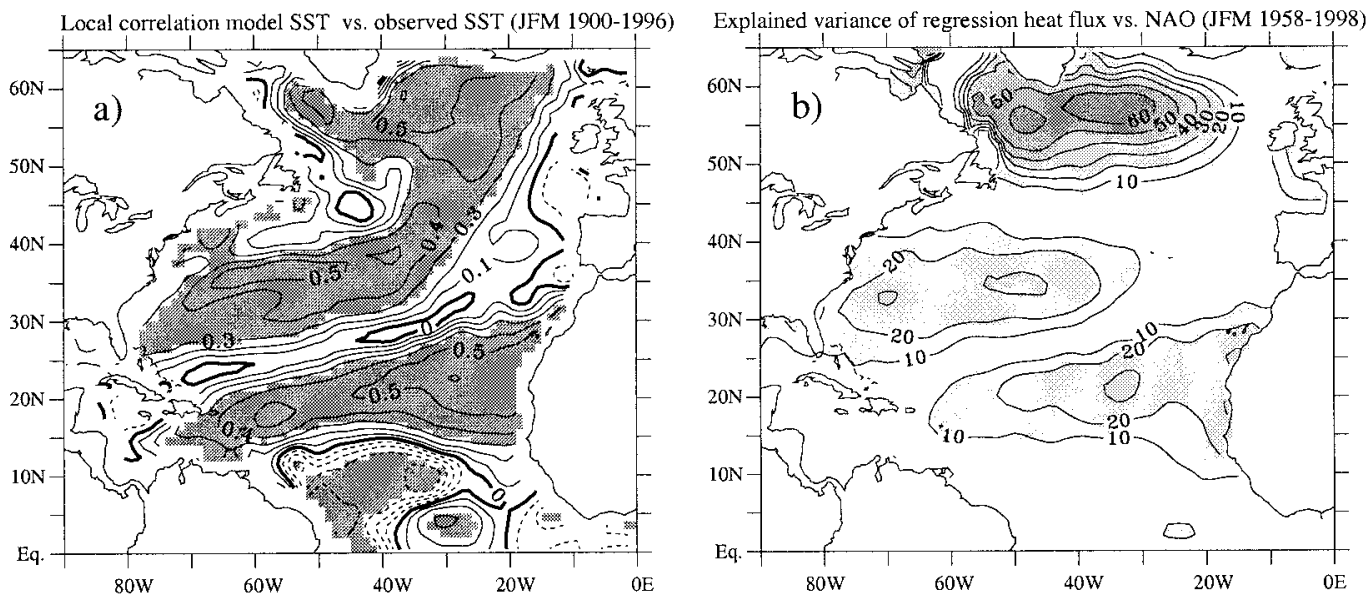

FIG. 1. (a) Local correlations between modeled and observed SST anomalies for winters (JFM) from 1900 to 1996. Correlations significant at the 95\% confidence level are shaded. (b) Percentage of observed net surface heat flux variance (\%) locally explained by the NAO index (winters JFM from 1958 to 1998).

tween the modeled THC strengths are $0.7-0.8$ in the northern North Atlantic, and cross correlations for MHT reach 0.9 near the North Atlantic subpolar front. Note, that no timescale dependence can be found for these correlations, as revealed by coherence spectra (not shown).

\section{Validation of modeled SST}

Observed SST fields (Rayner et al. 1996) during the period 1900-96 were used to evaluate the realism of the modeled SST anomalies during wintertime. Local correlations between modeled and observed SST anomalies for the winter seasons [January-February-March (JFM)] from 1900-96 are depicted in Fig. 1a. Statistically significant correlations, exceeding $r=0.5$, are located in the northern North Atlantic and the eastern subtropical North Atlantic. The western subtropical North Atlantic is another area of relatively high correlations. Common to all of these centers of action is the fact that the NAO explains relatively large amounts of the total surface net heat flux variability during wintertime (Fig. 1b). Hence, the agreement between modeled and observed SST anomalies may be simply the result of a realistic local heat flux forcing of the model's mixed layer by the wintertime NAO [see also Cayan (1992a) and Delworth (1996)]. An exception to this simple explantion, that is, a local forcing of the upper ocean by NAO-related net heat flux anomalies, is evident along the North Atlantic Current (NAC) between $40^{\circ}$ and $50^{\circ}$ N. Here, significant correlations are apparent, although no local net heat flux forcing was applied to the model. Therefore, the relatively high correlations in this region indicate a reasonable model response to a remote forcing by the NAO. In the following, it is shown that the realistic nonlocal model response may be understood in terms of a successful simulation of interdecadal changes of the North Atlantic Ocean during the twentieth century.

\section{Results}

\section{a. Observed and modeled interdecadal variability}

\section{1) NAO AND SST ANOMALIES}

The focus of this study is on interdecadal variability in the North Atlantic region. To (i) draw spectral characteristics from univariate and multivariate timeseries and to (ii) objectively separate interdecadal variability from higher-frequency fluctuations, singular spectrum analysis (SSA) and multichannel singular spectrum analysis (MSSA), respectively, were applied. Methodological details and references are given in the appendix. Since a window-width of $30 \mathrm{yr}$ was used in SSA and MSSA, hereafter, the term "interdecadal variability" refers roughly to variability with timescales longer than $30 \mathrm{yr}$.

The spectral characteristics of observed and modeled North Atlantic wintertime SST anomalies become evident from Fig. 2. Monte Carlo MSSA spectra are based on the leading 10 normalized ordinary principal components (S-PCs), explaining $85 \%$ (96\%) of the total observed (modeled) SST variance. Both observed and modeled North Atlantic SST anomalies show red noise background spectra, which are in very good agreement. Hence, primarily the stochastic forcing by the NAO seems to be responsible for the redness of North Atlantic SST anomalies. Moreover, observed and modeled spectral shapes are quite similar. Significant power on interdecadal and interannual (around 5-8, 3 , and 2.5 years) timescales is clearly evident from both the observations and the model. We do not want to go into too much statistical detail, since this study is primarily based on physical argumentation. However, it is worth mention- 

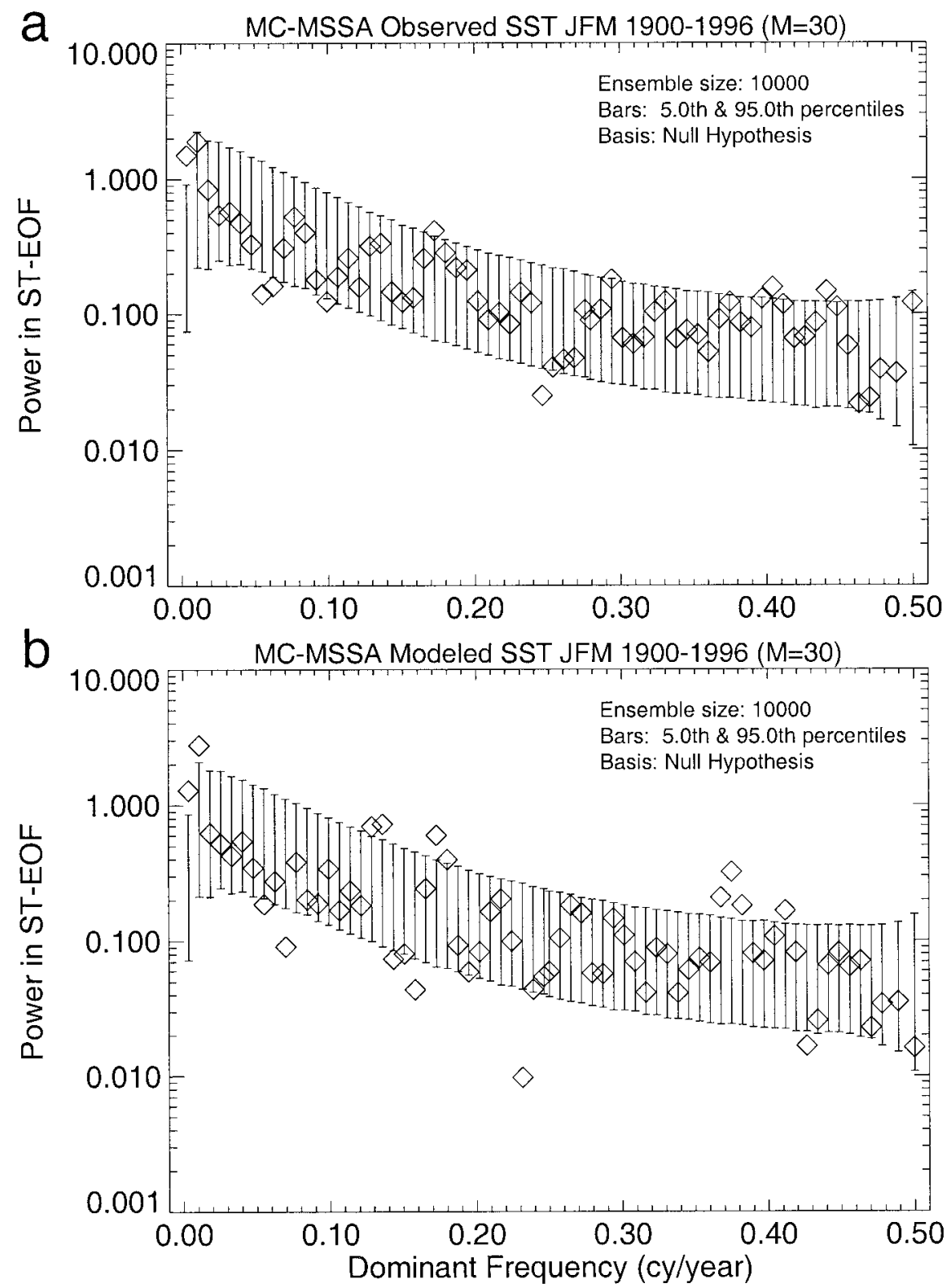

FIG. 2. Spectral characteristics of (a) observed and (b) modeled North Atlantic $\left(5^{\circ}-65^{\circ} \mathrm{N}, 100^{\circ} \mathrm{W}-\right.$ $20^{\circ} \mathrm{E}$ ) SST anomalies for winters (JFM) from 1900 to 1996, obtained by means of Monte Carlo MSSA. Diamonds denote the eigenvalues (power) of the data, plotted versus the dominant frequency (cy/yr). Percentiles (5th, 95th) were estimated from 10000 realizations of the null hypothesis, i.e., the leading 10 S-PCs $(L=10)$ of North Atlantic SST anomalies represent independent realizations of AR(1) noise. Both data and ensemble members were projected onto the ST-EOFs of the null hypothesis. A window length of $30 \mathrm{yr}(M=30)$ was used. Further methodological details and references are given in the appendix.

ing that the probability for 4 (Fig. 2a) or more local excursions (out of 68 possible) above the local $95 \%$ confidence level, as obtained for the observations, to occur just by chance is greater than $43 \%$. Therefore, without any a priori expectations, the leading $10 \mathrm{~S}-\mathrm{PCs}$ from the observations are not strongly unusual (at $57 \%$ confidence) compared to independent realizations of first-order autoregressive [AR(1)] noise. On the other hand, 10 excursions above the local 95\% confidence level are found for the modeled SST (Fig. 2b). The probability for 10 or more (out of 68) local excursions to occur just by chance under the global null hypothesis is less than $1 \%$. This indicates that other processes beside the integration of high-frequency atmospheric noise contribute to the spectral shapes depicted in Fig. 2.

To summarize, variability on interdecadal timescales 


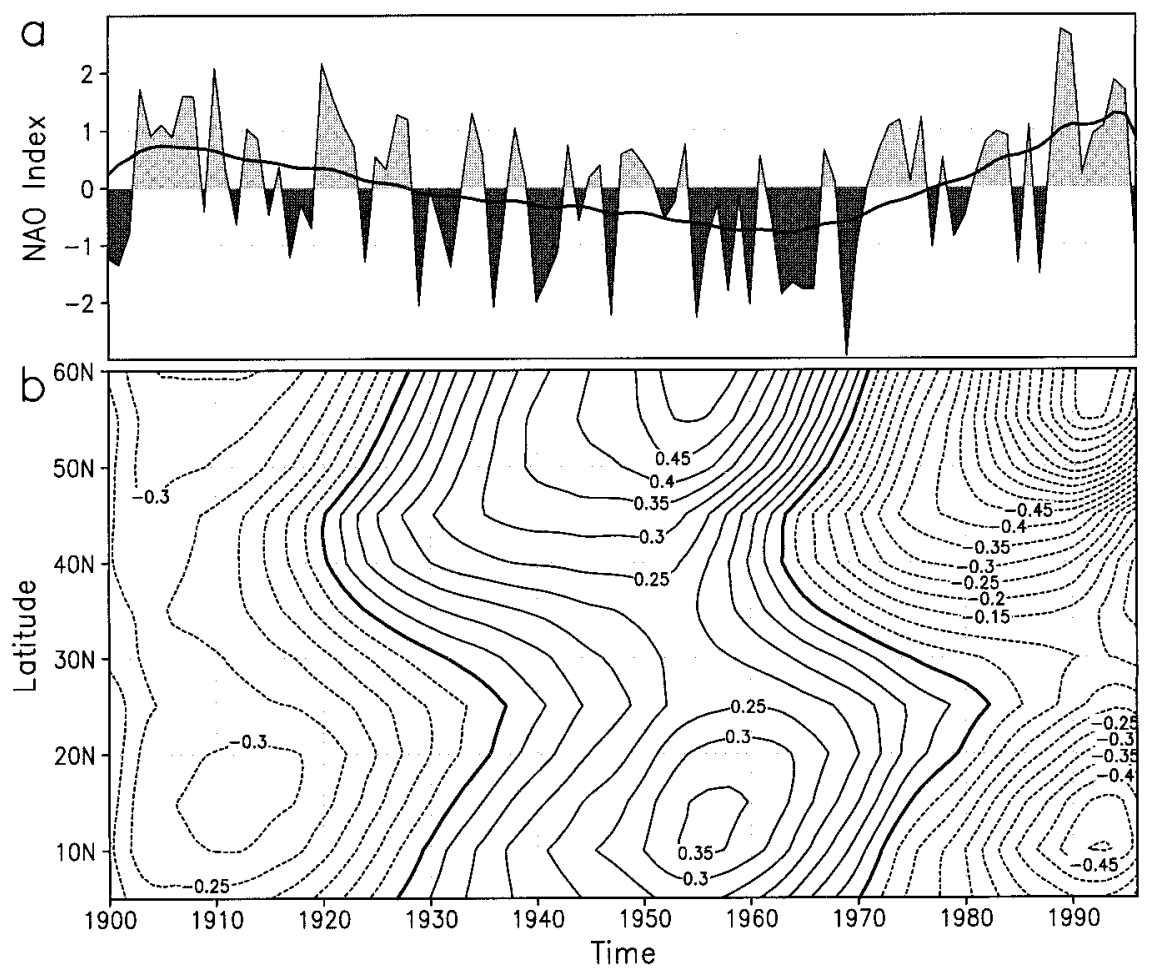

FIG. 3. Observed interdecadal variability of the NAO index and North Atlantic SST for winters (JFM) from 1900 to 1996. (a) Unfiltered NAO index (shaded) along with its interdecadal variability (solid). (b) Zonal average $\left(20^{\circ}-40^{\circ} \mathrm{W}\right)$ of observed interdecadal SST variability $\left({ }^{\circ} \mathrm{C}\right)$. Interdecadal NAO (SST) variability is based on the leading two SSA (MSSA) eigenmodes (see Fig. 2a for SST). A window width of $30 \mathrm{yr}(M=30)$ was used. The leading 10 normalized S-PCs of North Atlantic SST anomalies, explaining $85 \%$ of the total SST variance, were used. Methodological details are given in the appendix.

dominates observed and modeled SST anomalies. By applying Monte Carlo SSA, Jung and Ruprecht (1999) show that essentially the same holds for the wintertime NAO index. They found enhanced interdecadal variability, which is unusual (at $92.5 \%$ confidence) compared to realizations of AR(1) noise. After having described the spectral characteristics, SSA and MSSA is applied to separate interdecadal variability from higherfrequency fluctuations (low-pass filtering). This is achieved by reconstructing interdecadal variability from the leading two eigenmodes (see, e.g., Fig. 2 for SST) following the methods decribed in the appendix. Note that for all univariate and multivariate time series discussed in this study, the leading two (most energetic) eigenmodes represent interdecadal variability.

The wintertime NAO index and its interdecadal variability is shown in Fig. 3 together with zonally averaged $\left(20^{\circ}-40^{\circ} \mathrm{W}\right)$ observed interdecadal SST variability for winters (JFM) from 1900 to 1996. Interdecadal NAO (SST) variability explains $15 \%(25 \%)$ of the total variance. At the first glance, Fig. 3 may suggest a local relationship between an atmospheric forcing by the NAO and SST anomalies on interdecadal timescales. The persistent positive phases of the NAO during the beginning and end of the twentieth century [see also
Hurrell (1995) and Moron et al. (1998)] are accompanied by an anomalously cold subpolar and (eastern) subtropical North Atlantic. In both regions, interdecadal SST anomalies are positive during the persistent negative phase of the NAO $(\approx 1930-75)$. Hence, the existence of these SST anomalies may be partly explained by corresponding atmospheric changes [see also Cayan (1992b)].

The latitudinal dependence of the nodes, maxima, and minima of the observed interdecadal SST anomalies (Fig. 3b), which has been already noted by Kushnir (1994) [see also Moron et al. (1998)], indicates that oceanic dynamics contribute to the generation of interdecadal SST anomalies. In the northern North Atlantic $\left(50^{\circ}-60^{\circ} \mathrm{N}\right)$, there is a tendency for interdecadal SST anomalies to lead the NAO by a few years. The earliest precursors of these SST anomalies appear in the midlatitude North Atlantic $\left(40^{\circ}-45^{\circ} \mathrm{N}\right)$.

The observed and modeled wintertime (JFM) nearsurface cooling in the northern North Atlantic from 1960 to 1984 , which came in parallel with the change toward a high NAO (Fig. 3), is depicted in more detail in Fig. 4 . The corresponding warming during the period 191539 is quite similar (not shown), except for smaller magnitudes of the observed SST anomalies. The evolution 

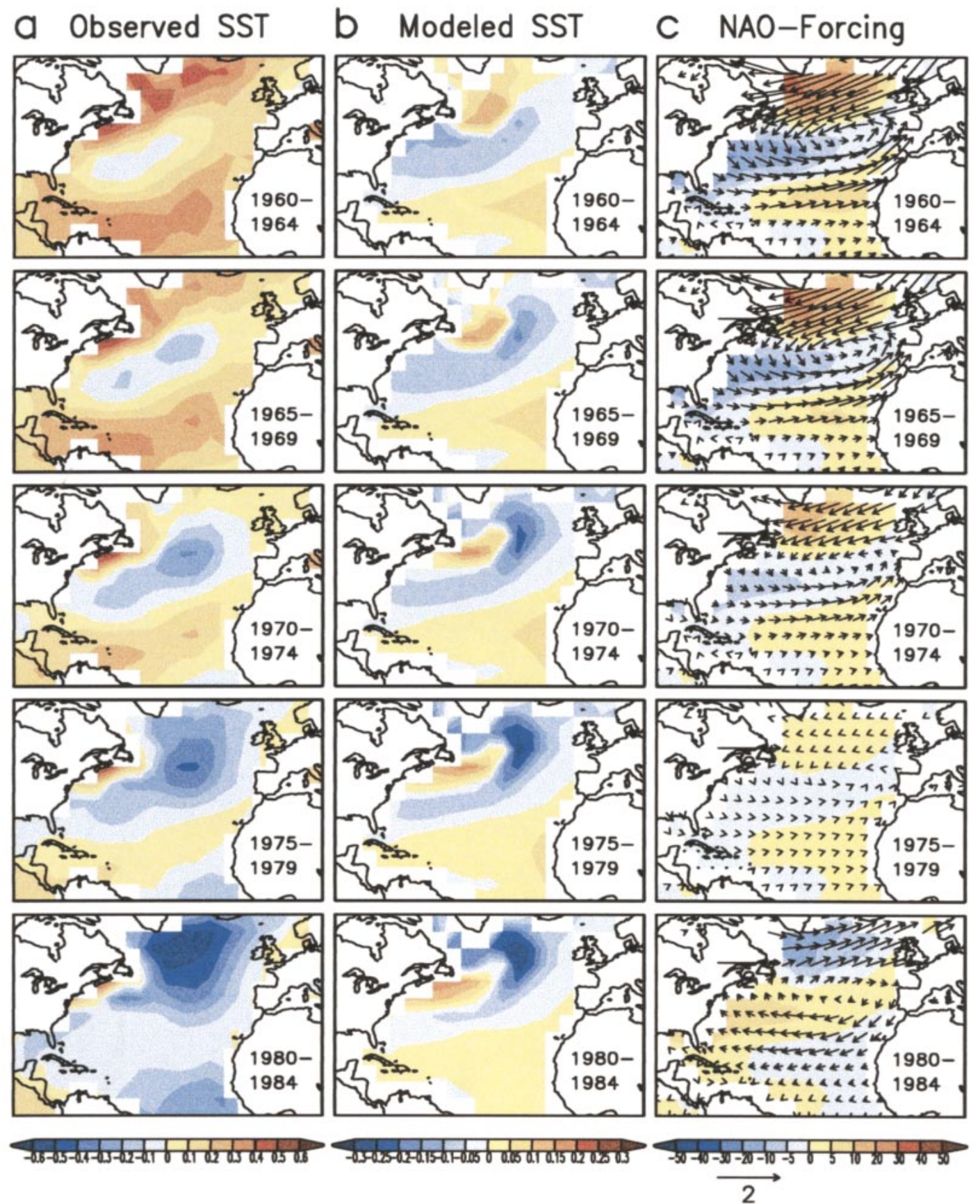

FIG. 4. Interdecadal variability of (a) observed and (b) modeled SST anomalies $\left({ }^{\circ} \mathrm{C}\right)$ for subsequent pentads during the period 1960-84 and wintertime (JFM), along with the (c) NAO-related interdecadal net heat flux ( $\mathrm{W} \mathrm{m}^{-2}$ ) and nearsurface wind $\left(\mathrm{m} \mathrm{s}^{-1}\right)$ fields. Interdecadal variability in (a) and (b) was reconstructed in the same manner as described in Fig. 3b. The leading 10 normalized S-PCs of observed (modeled) North Atlantic SST anomalies explain 86\% (95\%) of the total variance. In (c), interdecadal variability of the NAO index (Fig. 3a, solid) was multiplied by the anomalous fields of net surface heat flux as well as the zonal and meridional wind components associated with the NAO index (see section 2). Note the different contour spacing in (a) and (b).

of the observed interdecadal SST variability during the period 1960-84 is depicted in Fig. 4a, the middle column (Fig. 4b) shows the corresponding changes for the modeled SST, and the right column (Fig. 4c) shows the anomalous heat fluxes (positive, anomalous heating of the upper ocean) and 10-m winds that are associated with interdedadal NAO variability (forcing). The observed cooling of northern North Atlantic SSTs started (particularly) between the subtropical and subpolar gyre along the NAC during the 1960s. During the 1970s, the 
near-surface cooling took place primarily in the northern North Atlantic. Note that the appearence of this cold anomaly cannot entirely be explained by a local forcing from the NAO. First, there is no heat flux forcing associated with the NAO near $40^{\circ} \mathrm{N}$. Second, north of $50^{\circ} \mathrm{N}$, the anomalous NAO-related heat flux and windstress fields worked in such a way (1960-74) as to maintain the positive SST anomaly. Third, despite a missing forcing from the NAO during the pentad 1975-79, the observed cold SST anomaly continued to grow. Note that extratropical SST anomalies show typical $e$-folding times of a few months in the absence of any forcing (e.g., Frankignoul 1985).

The observed and modeled cooling of northern North Atlantic SSTs during the period 1960-84 are in good agreement (Figs. 4a,b). The magnitudes of the observed interdecadal SST anomalies, however, are about twice as large as those in the model. Smaller amplitudes of the modeled SST anomalies are presumably due to the relaxation toward climatological SSTs (surface boundary conditions). Note, however, that changes of the relaxation values for SST would be inconsistent with the linearization of the bulk parameterization of the heat flux components, and the SST would hardly be a prognostic variable of the model anymore. Although absolute values between modeled and observed SST anomalies differ, the relative contributions from interdecadal timescales to the total variance are comparable: Both modeled and observed interdecadal SST anomalies explain approximately $25 \%$ of the total SST variance in the North Atlantic during the winters from 1900 to 1996.

\section{2) NAO AND OCEANIC DYNAMICS}

The cooling (warming) of observed and modeled SSTs during the period 1960-84 (1915-39) (i) despite a missing NAO-related forcing along the NAC near $40^{\circ} \mathrm{N}$ and (ii) against the damping atmospheric forcing in the subpolar region $\left(50^{\circ}-60^{\circ} \mathrm{N}\right)$ supports the hypothesis that the North Atlantic Ocean contributes to the generation (maintenance) of North Atlantic SST anomalies on interdecadal timescales. Moreover, the agreement of the phase relationship between observed and modeled SST anomalies on interdecadal timescales (Fig. 4) enhances our confidence that the model results can be used to assess interdecadal variability of the oceanic circulation during the twentieth century.

The (unfiltered) wintertime NAO index and the strength of the annual-mean $\mathrm{THC}$ at $48^{\circ} \mathrm{N}$ and $1000-\mathrm{m}$ depth $\left(\mathrm{THC}_{48^{\circ} \mathrm{N}}\right)$ is shown in Fig. 5a. Obviously, interdecadal changes of the NAO lead those of $\mathrm{THC}_{48^{\circ} \mathrm{N}}$ by several years. The phase relationship on interdecadal timescales between the NAO and modeled time series of $\mathrm{THC}_{48^{\circ} \mathrm{N}}$, the meridional heat transport at $48^{\circ} \mathrm{N}$
$\left(\mathrm{MHT}_{48^{\circ} \mathrm{N}}\right)$, and the North Atlantic gyre strength ${ }^{1}\left(\psi_{\text {hor }}\right)$ becomes evident from Fig. 5b. All these integral oceanic parameters lag behind the NAO by 10-20 yr during the twentieth century. Furthermore, all oceanic time series are approximately in phase on interdecadal timescales. The persistent high NAO period during the beginning of the twentieth century, for example, is followed (after $\approx 20 \mathrm{yr}$ ) by an enhanced meridional and horizontal circulation in the North Atlantic and, therefore, an enhanced $\mathrm{MHT}_{48^{\circ} \mathrm{N}}$. The persistent period of a negative NAO around the early 1960 s is followed by a minimum $\mathrm{MHT}_{48^{\circ} \mathrm{N}}$ about $10 \mathrm{yr}$ later.

The gyre-strength index (Fig. 5b) suggests that the complete horizontal gyral circulation in the North Atlantic was involved. It is worth noting that this index primarily reflects variability in the horizontal ciculation north of $30^{\circ} \mathrm{N}$. This can be inferred from Fig. 6, where the difference of the horizontal streamfunction between its interdecadal low (1962-72) and high (1920-1930) epochs (cf. Fig. 5) is shown along with the long-term mean streamfunction.

In order to assess the relative contributions from the anomalous meridional and horizontal circulation to the total meridional heat transport, the total MHT was decomposed into its THC-related $\left(\mathrm{MHT}_{\text {over }}\right)$ and gyre-related $\left(\mathrm{MHT}_{\text {gyre }}\right)$ components (Bryan 1962). Here, $\mathrm{MHT}_{\text {over }}$ is defined as the product between the zonally averaged potential temperature and meridional velocity. The product between the corresponding deviations from the zonal average yields the gyre-related component to the total MHT. In the long-term mean, $\mathrm{MHT}_{\text {over }}$ dominates over $\mathrm{MHT}_{\text {gyre }}$ in the North Atlantic south of $45^{\circ} \mathrm{N}$. The $\mathrm{MHT}_{\text {gyre }}$ contributes approximately equally to the total MHT north of $45^{\circ} \mathrm{N}$ (not shown). Obviously, the same holds for variability of the MHT components on interdecadal timescales (Fig. 7). Furthermore, interdecadal variability of $\mathrm{MHT}_{\text {over }}$ spans the whole North Atlantic basin.

In order to clarify whether an advection of heat content anomalies was involved, the total MHT was decomposed into three parts: anomalous MHT due to the transport of temperature anomalies by the mean currents $\left(\bar{v} T^{\prime}\right)$, anomalous MHT due to an anomalous oceanic circulation $\left(v^{\prime} \bar{T}\right)$, and anomalous MHT due to covariances between anomalous currents and temperatures $\left(v^{\prime} T^{\prime}\right)$. The results from this decomposition (not shown) suggest that the bulk of interdecadal MHT variability in the North Atlantic is governed by changes of the circulation, $\left(v^{\prime} \bar{T}\right)$, whereas $\bar{v} T^{\prime}$ and $v^{\prime} T^{\prime}$ played a minor role.

To summarize, the near-surface cooling in the northern North Atlantic during the 1960s and 1970s was pre-

\footnotetext{
${ }^{1}$ The (North Atlantic) gyre strength was obtained by projecting anomalous annual-mean fields of the barotropic streamfunction onto the long-term mean streamfunction. Hence, this index gives a measure for the anomalous strength of the "mean" gyral circulation.
} 

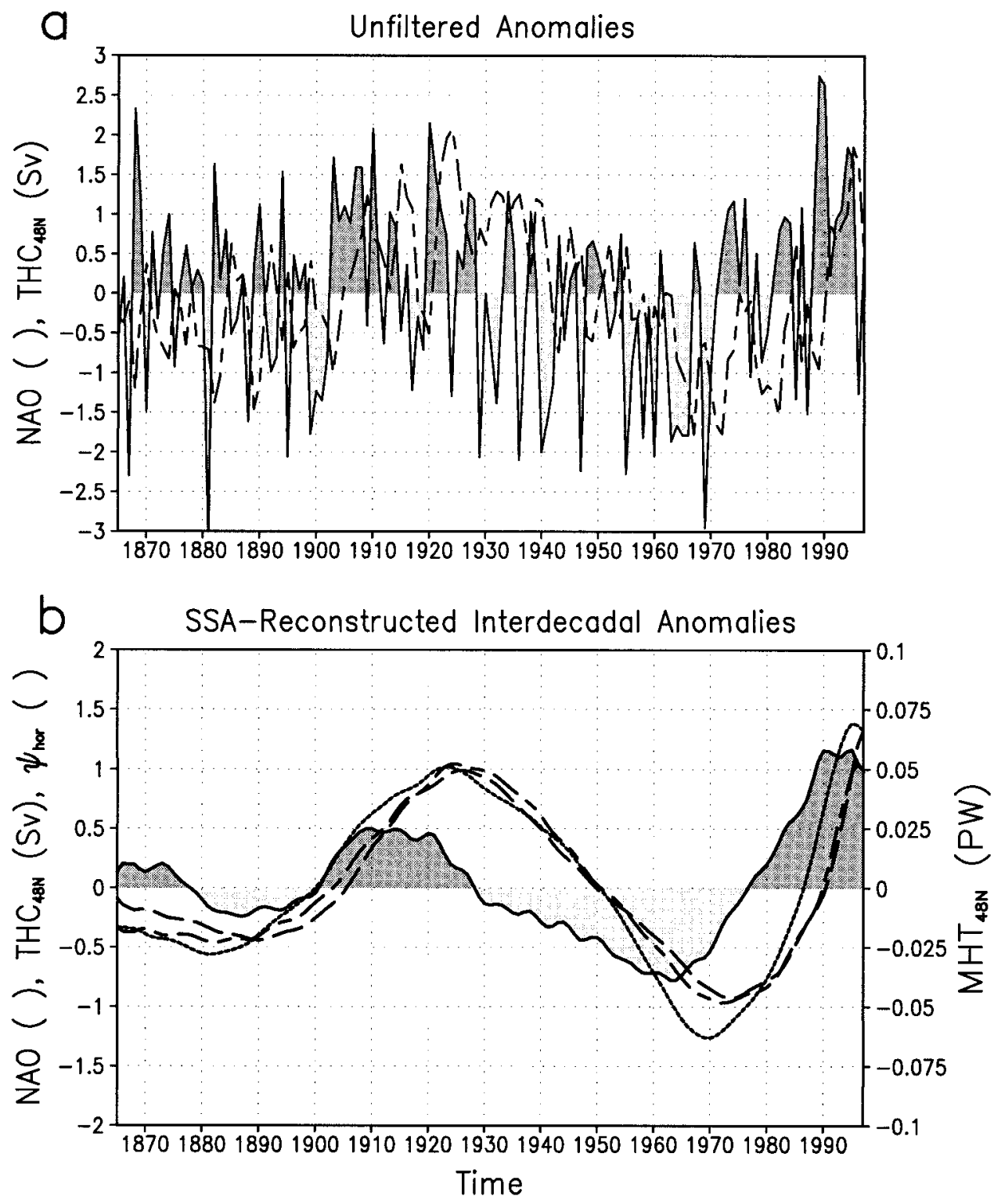

FIG. 5. Time series of the observed winter-averaged (JFM) NAO index and different modeled annual-mean oceanic parameters during the period 1865-1997. (a) Unfiltered NAO index (shaded) and Atlantic thermohaline circulation strength at $48^{\circ} \mathrm{N}\left(\mathrm{THC}_{48^{\circ} \mathrm{N}}\right.$ in $\mathrm{Sv} \equiv 10^{3} \mathrm{~m}^{3} \mathrm{~s}^{-1}$; long short dash). (b) Interdecadal variability of the NAO index (shaded), $\mathrm{THC}_{48^{\circ} \mathrm{N}}$ (in Sv; long short dash), and total meridional heat transport at $48^{\circ} \mathrm{N}\left(\mathrm{MHT}_{48^{\circ} \mathrm{N}}\right.$ in $\mathrm{PW} \equiv 10^{15} \mathrm{~W}$; long dash) along with the strength of the subtropical and subpolar gyres ( $\psi_{\text {hor }}$; dotted). Interdecadal variability was reconstructed, as decribed in Fig. 3a. From each of the oceanic time series, the linear trend was removed prior to the analysis.

sumably caused by the lagged response of the ocean to the persistent low NAO phase during the mid-twentieth century, that is, the weakening of the total MHT due to a reduced strength of the meridional and horizontal oceanic circulation. Similar arguments hold for the warming during the 1920s and 1930s.

The oceanic response to persistent NAO phases is discussed in more detail by EW. Enhanced convective activity in the Labrador Sea due to anomalously strong heat fluxes out of the ocean leads to a baroclinic bound- ary wave response, which propagates southward. As a consequence, the subpolar THC is enhanced after $3 \mathrm{yr}$. Moreover, the subpolar and subtropical gyres are enforced after a lag of 3-5 yr due to baroclinic processes. Both components are working in such a way as to increase the total $\mathrm{MHT}_{48^{\circ} \mathrm{N}}$. After a lag of about $10 \mathrm{yr}$, the baroclinic adjustment has completed, and there is a basinwide enhancement of the THC (see also Fig. 7).

This timescale-dependent relationship between the NAO and the MHT also becomes evident from the 

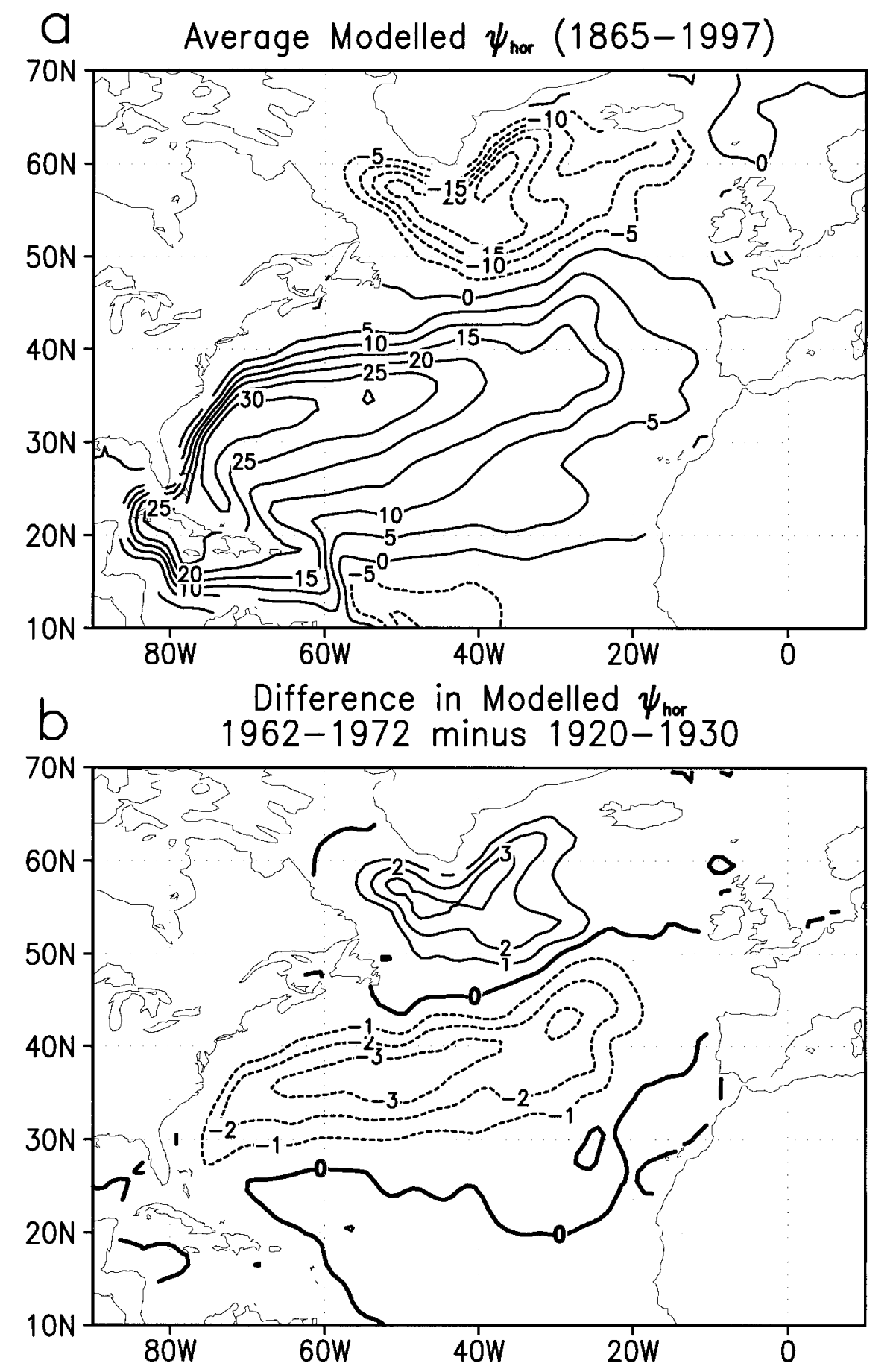

FIG. 6. Characteristics of the modeled annual-mean horizontal stream function (Sv): (a) Longterm average (1865-1997) and (b) difference between the interdecadal weak (1962-72) and strong (1920-30) decades of the modeled annual-mean horizontal streamfunction. Fields were smoothed using a nine-point filter (weighted sum).

model integration with the reconstructed NAO-like forcing over the period 1865-1997 (EXMAIN). The estimated squared coherency and phase spectra between the NAO index and the modeled total $\mathrm{MHT}_{48^{\circ} \mathrm{N}}$ are shown in Fig. 9. Whereas squared coherencies are significant over almost the whole frequency range, the phase relationship between the NAO and modeled total $\mathrm{MHT}_{48^{\circ} \mathrm{N}}$ is clearly timescale dependent. On interannual timescales, the NAO and the total $\mathrm{MHT}_{48^{\circ} \mathrm{N}}$ are approximately $180^{\circ}$ out-of-phase, that is, years with a 


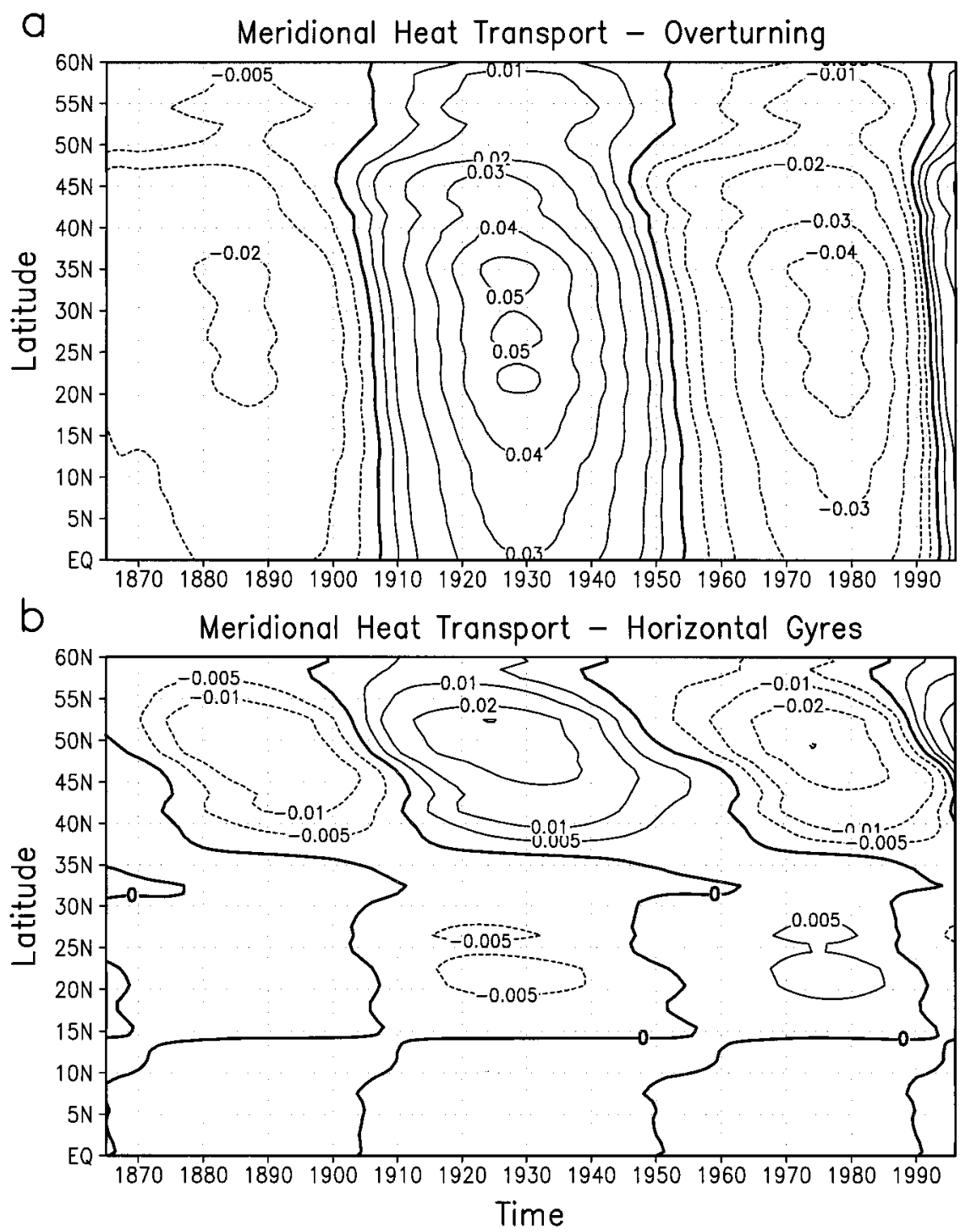

FIG. 7. Interdecadal variability of the modeled North Atlantic meridional heat transport (MHT) components: (a) overturning ( $\mathrm{MHT}_{\text {over }} 10^{15} \mathrm{~W}$ ), calculated from the products between zonal mean meridional velocities, $v$, and zonal mean temperature, $(T)$. (b) Gyre component (MHT $; 10^{15}$ $\mathrm{W})$, that is, covariance between the departures from the zonal mean $\left(v^{*} T^{*}\right)$. Interdecadal variability was reconstructed, as described in Fig. 3b, except that the first five normalized S-PCs, explaining 99.5\% (98\%) of the total $\mathrm{MHT}_{\text {over }}\left(\mathrm{MHT}_{\text {gyre }}\right)$ variance, were used. Linear trends were removed prior to the analysis.

high NAO index are accompanied by a reduced MHT and vice versa. On interdecadal timescales, however, the NAO leads the total $\mathrm{MHT}_{48^{\circ} \mathrm{N}}$ by approximately $60^{\circ}-80^{\circ}$ (i.e., $\approx 10-20 \mathrm{yr}$ for variability around $60-80$ yr).

\section{b. Sensitivity experiments}

\section{1) Role of the HeAt FluXes}

In the experiment described in the previous sections (hereafter EXMAIN), the model was solely forced with NAO-related heat flux, freshwater flux, and windstress variability. To assess the relative contributions from different surface flux components to the modeled interdecadal variability of the North Atlantic circulation, an additional experiment (hereafter EXHEAT) was performed. In EXHEAT, the model was solely forced by NAO-related heat flux variability; freshwater flux and windstress fields were prescibed as climatological annual cycles during the course of the integration.

Annual-mean values of the THC at $48^{\circ} \mathrm{N}$ and a depth of $1500 \mathrm{~m}$ are shown in Fig. 8 for EXMAIN (solid) and EXHEAT (dashed). Obviously, interdecadal changes of the THC are mainly driven by heat flux variability. The 


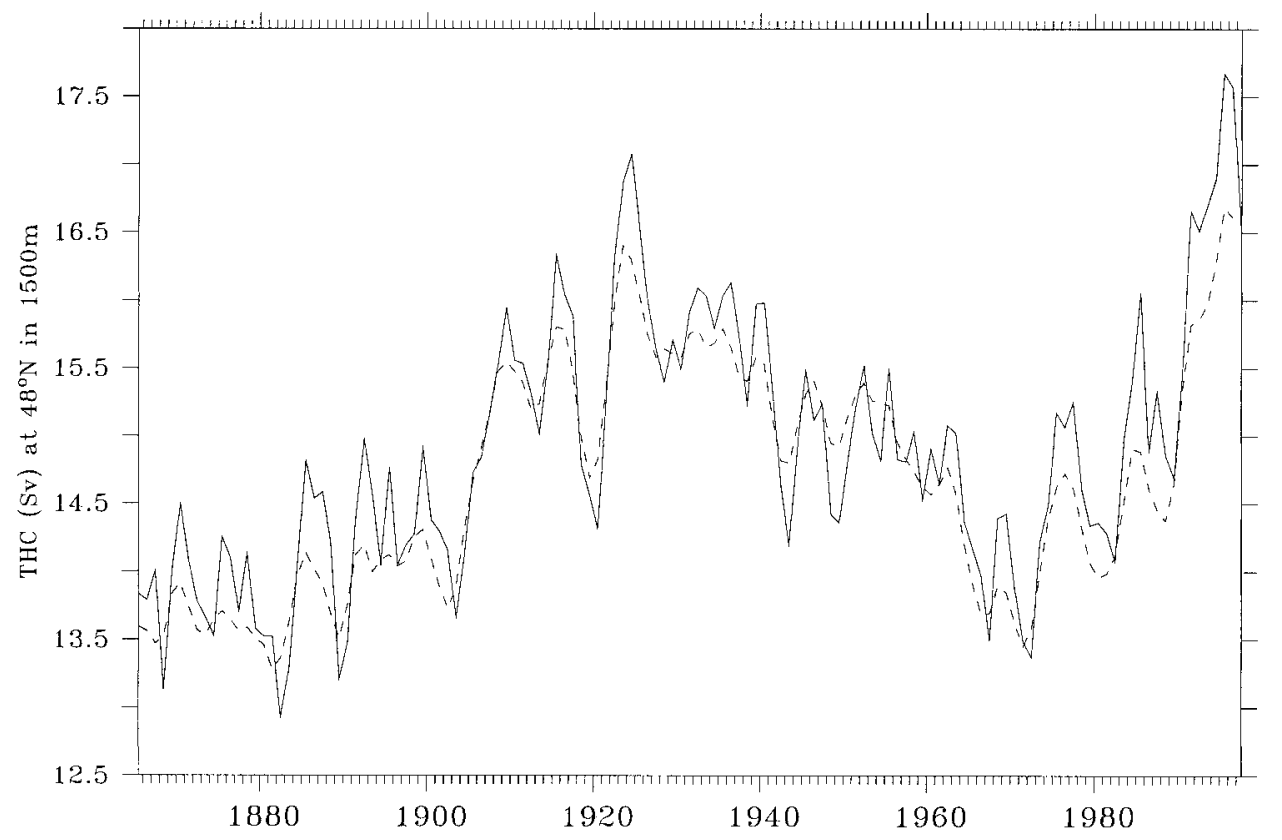

FIG. 8. Modeled strength of the annual-mean thermohaline circulation (Sv) at $48^{\circ} \mathrm{N}$ and $1500-\mathrm{m}$ depth with NAO-related net heat flux, wind stress, and freshwater flux forcing (solid) and with NAO-related heat flux forcing only (dashed).

NAO-related changes of freshwater flux and windstress fields are of minor importance.

For EXHEAT, the same analyses as described for EXMAIN were repeated. The interdecadal SST development for EXHEAT (not shown) is very similar to that for EXMAIN (Fig. 4). This similarity suggest that primarily NAO-related surface net heat flux anomalies drive interdecadal SST anomalies both indirectly, through the oceanic circulation (see above), and directly, through the air-sea interface.

\section{2) ROLE OF THE OVERFLOW}

A well-known drawback of OGCM's using $z$ levels is their inability to conserve the correct water mass characteristics while the cold and dense water overflows the northern sills like, for example, the Denmark Strait. It was shown by Döscher and Redler (1997) and Lohmann (1998) that the sensitivity of the thermohaline circulation to subpolar surface buoyancy forcing may change with a better representation of the effect of the dense overflow on the North Atlantic water mass structure. An attempt to overcome the overflow problem is the parameterization of bottom boundary layer (BBL) processes by Beckmann and Döscher (1997), which successfully suppresses an unrealistic warming of the cold overflow water while it descends. By using the BBL parameterization, the water mass characteristics of the model's lower NADW are conserved and in better agreement with observations (Dengg et al. 1999).

We performed an additional experiment, including the BBL parameterization of Beckmann and Döscher
(1997), and no significant changes of the variability of the large-scale oceanic circulation were found compared to EXMAIN. It is, however, worth noting that neither of the integrations account for possible changes of the water mass characteristics and strength of the overflow. This is because temperature and salinity were restored toward their climatogical annual cycle at the northern boundary of the model domain. However, the agreement between modeled and observed SST anomalies despite missing variability in the overlow lead us to speculate that overflow variability was of minor importance during the twentieth century, at least on interdecadal timescales.

\section{Conclusions}

A general circulation model for the Atlantic Ocean (OGCM) was solely forced with a realistic monthly NAO-like forcing over the period 1865-1997 in order to understand those oceanic processes that contributed to the observed interdecadal SST variability in the North Atlantic during the twentieth century. The following conclusions can be drawn.

- Apart from those regions where the OGCM was locally forced by NAO-related fluxes of heat, freshwater, and momentum through the air-sea interface, modeled and observed SST anomalies are consistent near the subpolar front along the North Atlantic Current (NAC), where a direct local forcing by the NAO is missing. Hence, we conclude that the response of the upper-ocean to a nonlocal forcing by the NAO 
(a)

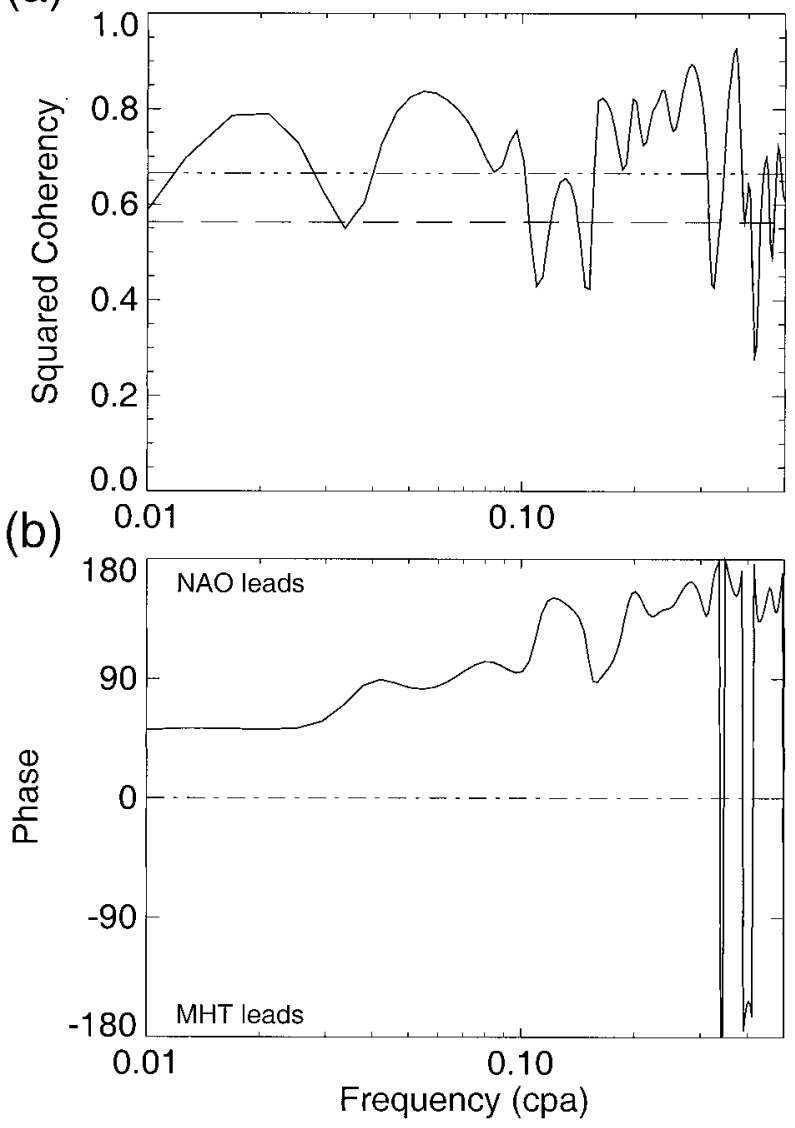

FIG. 9. Cross-spectral characteristics between the winter-averaged (JFM) NAO index and the modeled annual-mean meridional heat transport at $48^{\circ} \mathrm{N}$ for the period 1865-1997: (a) Estimated squared coherency spectrum with $95 \%$ (dashed) and $99 \%$ (dash dot) confidence levels and (b) estimated phase spectrum. The NAO index leads for positive phases. A Tukey window with a maximum lag of $40 \mathrm{yr}$ was used for smoothing ( 8.5 degrees of freedom). Time series were prewhitened prior to cross-spectral analysis. Methodological details are given, for example, by Jenkins and Watts (1968).

was successfully simulated, at least in this part of the North Atlantic.

- The development of observed and modeled SST anomalies during the periods 1915-39 and 1960-84 (i) against a direct local heat flux forcing from the NAO north of $40^{\circ} \mathrm{N}$ and (ii) despite a missing forcing from the NAO along the NAC near $40^{\circ} \mathrm{N}$ can be traced back to a lagged response $(\approx 10-20 \mathrm{yr})$ of the thermohaline circulation and subpolar gyre strength to interdecadal changes of the NAO. The contribution from interdecadal variability of the subtropical gyre to the meridional heat transport (MHT) was of minor importance.

- The oceanic response to interdecadal changes of the NAO is primarily driven by surface net heat flux variability. This finding is different compared to the oceanic variability on interannual timescales, where sur- face heat flux and windstress variability play a crucial role $(\mathrm{EW})$.

- Interdecadal variability of modeled oceanic quantities, like the THC, MHT, and gyre strength, amounts to approximately $10 \%$ of their long-term mean values.

- The presence of a better representation of the overflow over the northern sills does not have significant influence on the results.

\section{Discussion}

Interdecadal variability of the North Atlantic circulation and its relationship to the NAO is investigated by means of an OGCM that was solely forced by reconstructed NAO-related anomalous surface fluxes over the period 1865-1997.

Several simplifying assumptions are inherent to our experimental setup. First, it is assumed that the bulk of interdecadal oceanic variability is governed by the NAO. As noted in the introduction, this assumption is justified by previous observational and modeling studies. Our results provide further (a posteriori) evidence for the validity of this assumption. It is worth mentioning that the NAO index explains about $15 \%$ of the total net heat flux variance over the North Atlantic during the winter season (JFM). Thus, the OGCM was only forced with a relatively small amount of the total North Atlantic heat flux variability. Our result suggest that the dominant role of the NAO in forcing the North Atlantic circulation is associated with its strong modulation of net surface heat fluxes in the northwestern North Atlantic (Fig. 1b), where deep convection takes place. Second, it is assumed that interdecadal atmospheric variability can be described by the standing pattern of the NAO. We applied MSSA to wintertime (JFM) North Atlantic SLP fields [update from Trenberth and Paolino (1980)] for the period 1900-97. The dominant SLP mode explains $14 \%$ of the total SLP variance and describes interdecadal variability of the NAO (not shown). Thus, we are confident that the forcing fields used in this study account for the bulk of interdecadal atmospheric variability in the North Atlantic region. Third, the surface heat fluxes from the NCEP-NCAR reanalysis that were used to force the OGCM are to some degree influenced by the model physics of the reanalysis system (Kalnay et al. 1996). A comparison between the surface heat fluxes from the reanalysis and voluntary observing ship (VOS) data reveals a good agreement between the spatial patterns and temporal characteristics of North Atlantic heat flux variability (Gulev et al. 2000, manuscript submitted to J. Phys. Oceanogr.). Thus, we are confident that the reanalyzed surface heat fluxes capture the bulk of NAO-related heat flux variability in the North Atlantic region. Finally, we have to note that any direct impacts from the variability of the overflow and freshwater intrusion from high latitudes (north of $70^{\circ} \mathrm{N}$ ) were neglected. We did not take into account, for example, the direct effect of the "Great Salinity Anomaly" 
(GSA), which passed the Labrador Sea during the early 1970s (Dickson 1988). We cannot exclude that the effect of the GSA is inherent to the forcing fields through an impact onto the SST and/or atmospheric parameters. However, according to our OGCM experiments, the $d i$ rect influence from the GSA in the Labrador Sea region was presumably of minor importance for interdecadal variability of the North Atlantic Ocean. Although some of the simplifications may appear rather crude, the agreement between observed and modeled key aspects of interdecadal SST variability enhances our confidence that the modeled interdecadal variability of the oceanic circulation as a response to a forcing by the NAO is realistic.

It is shown that (i) interdecadal changes in the circulation of the North Atlantic ocean leave their imprint on the sea surface (SST anomalies) and (ii) oceanic changes lag behind the NAO. This may explain why previous observational studies (Bjerknes 1964; Deser and Blackmon 1993; Kushnir 1994) successfully identified oceanic dynamics to play an important role for North Atlantic interdecadal variability. Moreover, the appearence of interdecadal oceanic variability on the sea surface allows the assessment of forced OGCM experiments during the twentieth century, at least to some degree. Our results essentially confirm Kushnir's hypothesis that interdecadal variability of the North Atlantic Ocean is primarily governed by changes in the THC and NAO. Changes in the MHT due to interdecadal variability of the subpolar gyre, however, seem to be of importance too. In contrast to Bjerknes' original hypothesis, the results from this study indicate that interdecadal variability of the subtropical gyre contributes rather little to the North Atlantic MHT (Fig. 7b) and, thus, to North Atlantic interdecadal SST anomalies.

Our finding that interdecadal oceanic changes lag behind the NAO by several years (Fig. 5) imply that the definition of epochs for subsequent composite analyses, which are based on sea surface data alone, may mix the instantaneous impact from the NAO and the delayed impact from the ocean. Hence, such composite analyses may ineffectively describe the extreme anomalies in the atmosphere and those in the ocean. Provided that the model performed realistically, the stongest interdecadal changes in the North Atlantic Ocean should be found by analyzing the difference of subsurface data between the 1990s and the late 1960s to early 1970s (Fig. 5b). Such an analysis, which could shed further light on the water masses that are involved in North Atlantic interdecadal variability, however, goes beyond the scope of the present study.

A relatively strong two-way interaction between the NAO and the THC on interdecadal timescales was found by Timmermann et al. (1998) in an integration with the coupled ECHAM3/LSG model. In agreement with the results from this study, in their model, the NAO alters the strength of the THC after some delay, although the physics involved are different. ${ }^{2}$ In the ECHAM3/LSG model, the NAO and the THC are approximately in phase on interdecadal timescales. This is because the atmospheric response to an anomalously strong (weak) THC involves a strenghtened (weakened) NAO in the ECHAM3/LSG model. From our results, there is less indication that the NAO and the THC covary in phase on interdecadal timescales, although some uncertainties remain due to the shortness of the time series used here (one realization is considered). We found no pronounced NAO anomalies during periods of an anomalously strong (1925-35) and weak (1965-75) THC (Fig. 5b), respectively. This suggests that the instantaneous response of the NAO to interdecadal variability of the $\mathrm{THC}$ is rather weak.

It is shown that interdecadal SST anomalies lead the NAO by a few years in the northern North Atlantic during the twentieth century, particularly around $40^{\circ} \mathrm{N}$ (Figs. 3 and 4). We propose that this is not due to a forcing of the NAO by the ocean. Rather, this phase relationship may be explained by a superposition of two processes: the instantaneous thermal response of the upper ocean along with the lagged response of the North Atlantic circulation to the same forcing, interdecadal variability of NAO-related surface net heat fluxes. During the 1960s, for example, the westerly winds (NAO) were reduced, which supported a warming of the northern North Atlantic via reduced net heat fluxes out of the ocean (Fig. 4). At the same time Labrador Sea convection was also reduced. Thus, the North Atlantic MHT continued to decline (Fig. 5b), leading to a near-surface cooling of the northern North Atlantic (Fig. 4). The cooling of northern North Atlantic SSTs due to NAOrelated anomalous heat fluxes out of the ocean started later, that is, after the late 1970s. Thus, SST anomalies lead the NAO on interdecadal timescales. Note, however, that this phase relationship on interdecadal timescales may be explained by a one-way forcing of the North Atlantic Ocean by NAO-related surface net heat fluxes.

To summarize from the results of this study, the simplest way to explain interdecadal variability of the North Atlantic circulation is as follows. Interdecadal variability of the North Atlantic circulation is the lagged (passive) response to a surface heat flux forcing associated with interdecadal variability of the NAO. A similar explanation has been put forward by Delworth and Greatbatch (2000). Thus, our results imply that forcing candidates other than the North Atlantic Ocean should also be taken into account in order to explain the pronounced interdecadal variability of the NAO during the twentieth century.

Acknowledgments. Helpful discussions with J. Wil-

\footnotetext{
${ }^{2}$ In the ECHAM3/LSG model, surface freshwater fluxes and Ekman transports associated with the NAO play the major role.
} 
lebrand and E. Ruprecht as well as A. Timmermann and S. K. Gulev are very much appreciated. A. Oschlies, C. Voelker, M. Hilmer, and L. Hasse provided valuable comments on earlier versions of the manuscript. Thanks to two anonymous reviewers, whose comments contributed to the clarity of the manuscript. We greatly acknowledge the FLAME group, especially the work of R. Redler, for model development. NCEP-NCAR reanalysis data were provided through the NOAA Climate Diagnostics Center (http://www.cdc.noaa.gov/). This is a contribution of the Sonderforschungsbereich 460 "Dynamics of Thermohaline Circulation Variability" at the University of Kiel (http://www.ifm.uni-kiel.de/ general/sfb460-e.html) supported by the German Research Foundation.

\section{APPENDIX}

\section{Statistical Methods}

A common task in climate research is to separate nonlinear trends and modulated oscillations from the background noise. Here, singular spectrum analysis (SSA) (e.g., Broomhead and King 1986; Vautard 1995) and multichannel singular spectrum analysis (MSSA) (e.g., Plaut and Vautard 1994; Vautard 1995; Moron et al.1998) were applied to objectively separate interdecadal variability from higher-frequency fluctuations, that is, to objectively low-pass filter univariate and multivariate time series, respectively.

The SSA is based on sliding a window of length $M$ (maximum lag) down a time series of length $N$ and looking for recurrent "patterns in time." From these "views" through the window, the recurrent patterns are described by the temporal eigenvectors (T-EOFs) of the time series' $(M \times M)$ lag-covariance matrix. The corresponding $M$ eigenvalues, $\lambda^{m}$, are arranged in decreasing order and give the associated variances. The $M$ principal components $\left(\mathrm{T}-\mathrm{PC}^{m}\right)$ of length $N-M+1$ are obtained by projecting the original time series onto the corresponding $\mathrm{T}^{-\mathrm{EOF}^{m}}$. Each T-PC represents a (objectively) filtered version of the original time series. The main task in SSA is to identify those eigenmodes, $m$, which represent the signal. Inference about the significance of specific eigenmodes can be drawn from Monte Carlo tests (see below). Once signal modes have been identified, the signal part of the time series can be recontructed $\left(\mathrm{T}-\mathrm{RC}^{m}\right)$. The T-RCs are of length $N$ and contain information about the phase (e.g., Vautard 1995). In this study, a window length of $M=30 \mathrm{yr}$ is used. Hence, interdecadal variability is actually reconstructed from T-EOFs, which represent nonlinear trends. The dominant frequency associated with each signal mode is estimated from the corresponding T-EOFs by means of the reduced Fourier transform (Plaut and Vau$\operatorname{tard} 1994)$.

The MSSA is the multivariate extension of SSA. To enhance the signal-to-noise ratio and to reduce the spa- tial degrees of freedom, all multivariate fields are subject to an ordinary empirical orthogonal function analysis prior to the MSSA. The resulting ordinary (spatial) PCs and EOFs are denoted as S-PCs and S-EOFs, respectively. Since only the leading $L$ S-PCs are used as input for the MSSA, the number of spatial degrees of freedom is reduced to $L$. In MSSA, the diagonalization of the $(L M \times L M)$ lag cross-covariance yields the corresponding ST-EOFs from which the ST-PCs and ST-RCs are calculated in the same way as for SSA. For each of the $L$ input channels, the temporal interdecadal variability was reconstructed (ST-RCs). Finally, the spatiotemporal interdecadal development was reconstructed by multiplying the $L$ interdecadal ST-RCs with the $L$ spatial S-EOFs (Moron et al. 1998).

The SSA and the MSSA provide a natural framework to test the significance of individual eigenmodes against different null hypotheses by means of Monte Carlo procedures (Allen and Smith 1996; Allen and Robertson 1996). Here, we test univariate time series against AR(1) noise (Monte Carlo SSA) and the $L$ S-PCs against $L$ independent realizations of $\mathrm{AR}(1)$ noise (Monte Carlo MSSA). The corresponding AR(1) parameters were estimated from the data following Allen and Smith (1996). Percentiles for each eigenvalue, $\lambda^{k}$, were obtained from a large number of realizations of the null hypothesis. Both the realization of the null hypothesis and the original timeseries were projected onto the basis (T-EOFs; (ST-EOFs) of the null hypothesis (Allen and Smith 1996; Allen and Robertson 1996) to avoid the variance compression problem, that is, to operate as close as possible near the nominal confidence level (Allen and Smith 1996).

\section{REFERENCES}

Allen, M. R., and A. W. Robertson, 1996: Distinguishing modulated oscillations from coloured noise in multivariate datasets. Climate Dyn., 12, 775-784.

_ and L. A. Smith, 1996: Monte Carlo SSA: Detecting irregular oscillations in the presence of colored noise. J. Climate, 9, 33733404.

Barnier, B., L. Siefridt, and P. Marchesiello, 1995: Thermal forcing for a global ocean circulation model using a three year climatology of ECMWF analysis. J. Mar. Syst., 6, 363-380.

Beckmann, A., and R. A. Döscher, 1997: A method for improved representation of dense water spreading over topography in geopotential-coordinate models. J. Phys. Oceanogr., 27, 581-591.

Bjerknes, J., 1964: Atlantic air sea interaction. Advances in Geophysics, Vol. 10, Academic Press, 1-82.

Broomhead, D. S., and G. King, 1986: Extracting qualitative dynamics from experimental data. Physica D, 20, 217-236.

Bryan, K., 1962: Measurements of meridional heat transport by ocean currents. J. Geophys. Res., 67, 3403-3414.

Cayan, D. R., 1992a: Latent and sensible heat flux anomalies over the northern oceans: Driving the sea surface temperature. J. Phys. Oceanogr., 22, 859-881.

- 1992b: Latent and sensible heat flux anomalies over the northern oceans: The connection to monthly atmospheric circulation. J. Climate, 5, 354-369.

Cox, M., 1987: Isopycnal diffusion in a z-coordinate ocean model. Ocean Model., 74, 1-5. 
Curry, R. G., M. S. McCartney, and T. M. Joyce, 1998: Oceanic transport of subpolar climate signals to mid-depth subtropical waters. Nature, 391, 575-577.

Delworth, T. L., 1996: North Atlantic interannual variability in a coupled ocean-atmosphere model. J. Climate, 9, 2356-2375.

— lation variability driven by atmospheric surface flux forcing. $J$. Climate, 13, 1481-1495.

— S. Manabe, and R. J. Stouffer, 1993: Interdecadal variations of the thermohaline circulation in a coupled ocean-atmosphere model. J. Climate, 6, 1993-2011.

,$- \ldots$, and -1997 : Multidecadal climate variability in the Greenland Sea and surrounding regions: A coupled model simulation. Geophys. Res. Lett., 24, 257-261.

Dengg, J., C. Boening, U. Ernst, R. Redler, and A. Beckmann, 1999: Effects of an improved model representation of Overflow waters on the subpolar North Atlantic. WOCE Newsl., 37, 10-15.

Deser, C., and M. L. Blackmon, 1993: Surface climate variability over the North Atlantic Ocean during winter: 1900-1989. J. Climate, 6, 1743-1753.

Dickson, R., 1988: Great Salinity Anomaly in the northern North Atlantic 1968-1982. Progress in Oceanography, Vol. 20, Pergamon, 103-151.

_ _ J. Lazier, J. Meincke, P. Rhines, and J. Swift, 1996: Long-term coordinated changes in the convective activity of the North Atlantic. Progress in Oceanography, Vol. 38, Pergamon, 241-295.

Döscher, R., and R. Redler, 1997: The relative influence of North Atlantic overflow and subpolar deep convection on the thermohaline circulation in an OGCM. J. Phys. Oceanogr., 27, 1894-1902.

Eden, C., and J. Willebrand, 2001: Mechanism of interannual to decadal variability of the North Atlantic circulation. J. Climate, in press.

Frankignoul, C., 1985: Sea surface temperature anomalies, planetary waves, and air-sea feedback in the middle latitudes. Rev. Geophys., 23, 357-390.

Gargett, A., 1984: Vertical eddy diffusivity in the ocean interior. $J$. Mar. Res., 42, 359-393.

Gent, P., and J. McWilliams, 1990: Isopycnal mixing in ocean circulation models. J. Phys. Oceanogr., 20, 150-155.

Grötzner, A., M. Latif, and T. P. Barnett, 1998: A decadal climate cycle in the North Atlantic ocean as simulated by the ECHO coupled GCM. J. Climate, 11, 831-847.

Häkkinen, S., 1999: Variability of the simulated meridional heat transport in the North Atlantic for the period 1951-1993. J. Geophys. Res., 104, 10 991-11007.

Halliwell, G. R., 1998: Simulation of North Atlantic decadal/multidecadal winter SST anomalies driven by basin-scale atmospheric circulation anomalies. J. Phys. Oceanogr., 28, 5-21.

Haney, R., 1971: Surface thermal boundary condition for ocean circulation models. J. Phys. Oceanogr., 1, 79-93.

Hurrell, J. W., 1995: Decadal trends in the North Atlantic Oscillation: Regional temperatures and precipitation. Science, 269, 676-679.

— with the North Atlantic Oscillation. Climatic Change, 36, 301326.

Jenkins, G. M., and D. G. Watts, 1968: Spectral Analysis and its Application. Holden-Day, 525 pp.

Jones, P. D., T. Jonsson, and D. Wheeler, 1997: Extension to the North Atlantic Oscillation using early instrumental pressure observa- tions from Gibraltar and south-west Iceland. Int. J. Climatol., 17, 1433-1450.

Jung, T., and E. Ruprecht, 1999: On the nature of the North Atlantic Oscillation and its interdecadal variability. Preprints, 10th Symp. on Global Change Studies, Dallas, TX, Amer. Meteor. Soc., 143146.

Kalnay, E., and Coauthors, 1996: The NCEP/NCAR 40-Year Reanalysis Project. Bull. Amer. Meteor. Soc., 77, 437-471.

Kraus, E., and J. Turner, 1967: A one-dimensional model of the seasonal thermocline II, the general theory and its consequences. Tellus, 19, 98-105.

Kushnir, Y., 1994: Interdecadal variations in North Atlantic surface temperature and associated atmospheric conditions. J. Climate, 7, 141-157.

, R. Seager, M. Visbeck, N. Naik, and J. Miller, 1999: Modeling Atlantic ocean SST variability 1958-1998. Preprints, Eighth Conf. on Climate Variations, Denver, CO, Amer. Meteor. Soc., $172-175$.

Latif, M., and T. P. Barnett, 1994: Causes of decadal climate variability over the North Pacific and North America. Science, 266, 634-637.

Lohmann, G., 1998: The influence of a near-bottom transport parameterization on the sensitivity of the thermohaline circulation. $J$. Phys. Oceanogr., 28, 2095-2103.

Moron, V., R. Vautard, and M. Ghil, 1998: Trends, interdecadal and interannual oscillation in global sea-surface temperatures. $\mathrm{Cli}$ mate Dyn., 14, 545-569.

Pacanowski, R., 1995: MOM 2 Documentation, User's Guide and Reference Manual. Tech. Rep. 3, GFDL Ocean Group, GFDL, Princeton, NJ, 232 pp. [Available from NOAA/GFDL, P.O. Box 308, Princeton, NJ 08542-0308.]

Plaut, G., and R. Vautard, 1994: Spells of low-frequency oscillations and weather regimes in the Northern Hemisphere. J. Atmos. Sci., $\mathbf{5 1}, 210-236$

Rahmstorf, S., and J. Willebrand, 1995: The role of temperature feedback in stabilizing the thermohaline circulation. J. Phys. Oceanogr., 25, 787-805.

Rayner, N. A., E. B. Horton, D. E. Parker, C. K. Folland, and R. B. Hacket, 1996: Version 2.2 of the global sea-ice and sea surface temperature data set, 1903-1994. Tech. Note 74, Hadley Center for Climate Prediction and Research, $29 \mathrm{pp}$. [Available from Hadley Centre, Meteorological Office, London Road, Bracknell, Berkshire RG 12 2SY, United Kingdom.]

Rogers, J. C., 1984: The association between the North Atlantic Oscillation and the Southern Oscillation in the Northern Hemisphere. Mon. Wea. Rev., 112, 1999-2015.

Seager, R., M. Blumenthal, and Y. Kushnir, 1995: An advective atmospheric mixed layer model for ocean modeling purpose: Global simulation of surface heat fluxes. J. Climate, 8, 1951-1964.

Stevens, D. P., 1990: On open boundary conditions for three dimensional primitive equation ocean circulation models. Geophys. Astrophys. Fluid Dyn., 51, 103-133.

Timmermann, A., M. Latif, R. Voss, and A. Grötzner, 1998: Northern Hemispheric interdecadal variability: A coupled air-sea mode. J. Climate, 11, 1906-1931.

Trenberth, K. E., and D. A. Paolino, 1980: The Northern Hemisphere sea-level pressure data set: Trends, errors and discontinuities. Mon. Wea. Rev., 108, 855-872.

Vautard, R., 1995: Patterns in time: SSA and MSSA. Analysis of Climate Variability: Application of Statistical Techniques, $\mathrm{H}$. von Storch and A. Navarra, Eds., Springer Verlag, 259-279.

Walker, G. T., 1924: Correlation in seasonal variation of weather, IX. Mem. Indian Meteor. Dept., 24, 275-332. 